\title{
A Review of Outcome of Postgraduate Medical Training in Zambia
}

\author{
Bowa $\mathrm{K}^{1}$, Goma F, Yikona $\mathrm{JINM}^{2}$, Mulla $\mathrm{Y} \mathrm{F}^{1}$ and Banda $\mathrm{S} \mathrm{S}^{1}$. \\ ${ }^{1}$ University of Zambia, School of Medicine, ${ }^{2}$ Consultant Physician, UK
}

\begin{abstract}
The University of Zambia School of Medicine was opened in 1966. Since inception, over 1200 undergraduate students have graduated with Bachelor of Medicine and Bachelor of Surgery. The postgraduate Master of Medicine (M.Med)programme was started in $1982^{2}$ with the intention of providing district specialists in the rural and semi urban communities of Zambia. Additional hope was to stem the brain drain to other countries.
\end{abstract}

This is a study to describe the deployment of graduates of the M.Med training programs at the University of Zambia School Of Medicine in relation to the objectives defined by the University of Zambia senate in 1981.

It was found that the School of Medicine has produced 118 Master of Medicine graduates in 5 clinical programs over a period of 22 years. The average graduation rate is 5 students per annum. The largest specialist group has been in General surgery with $34(29 \%)$ of all graduates. The ratio of men to women was 3 to 1 . The ratio of Zambian to Non Zambian ratio was 10:1. Of all students who have graduated over this period $13(11 \%)$ have gone abroad and $7(6 \%)$ have died., Eighty-eight $(75 \%)$ of the graduates are working along the line of rail in the 5 most urbanized towns in the country.

Twenty-five ( $21 \%$ ) are doing non clinical jobs which involve health programs administration and $12(10 \%)$ are working in private practice.

\section{Corresponding Author:}

Dr. Kasonde Bowa

Department of Surgery

University Teaching Hospital, Lusaka, zambia

E-mail: kasondebowa@yahoo.com
We concluded that external migration is not a major problem and, overall, the creation of a local postgraduate training program has reduced brain drain. The key challenge is internal brain drain.

\section{INTRODUCTION}

Zambia is a landlocked country in Southern Africa covering an area of 752,612 square kilometres ( six times the size of the United Kingdom). It has a population of 12 million and a per capita income of 490USD dollars per capita. Over $73 \%$ of it's population are classified by UN criteria as poor ${ }^{3}$. There are 1,285 health institutions, the smallest unit is the health post. There are 9 health posts, the next level of care is the health centres, of which there are 1086. The third level of care is the district hospital,numbering 42 such institutions. They are 18 general hospitals, 3 central hospitals and 4 specialised hospitals. In addition there are 19 mission hospitals ${ }^{3}$.

The country has 3 public universities and 3 private universities. Only one university runs a medical school. That is the University of Zambia. There are 1390 medical doctors practicing in Zambia. The current doctor to population ratio is 1 to 17,589 . The World Health Organisation recommends 1 doctor to every 5,000 people.

The school of medicine of the University of Zambia was opened in 1966 and had it's first 13 graduates in 1973. In its 42 years, it has produced over 1200 medical graduates. The postgraduate programme was started in 1982. The programme now has 11 postgraduate programmes. There are six Master of Medicine (M.Med) programs at the University of

\section{Keywords}

Postgraduate training, Master of Medicine, Brain Drain. 
Zambia school of Medicine, these are in Paediatrics, Internal Medicine, Obstetrics and Gynaecology, General Surgery, Orthopaedics and Urology. ${ }^{1,2}$.

The Master of Medicine program is the clinical specialist postgraduate training which was modeled on the old United Kingdom Royal Colleges system. It is a 4 year hospital based training following which the graduate is appointed Senior Registrar. All graduates were normally accorded clinical experience of medical practice abroad. The Senior Registrar is appointed Consultant 2 years after completion. Similar programs are offered in the subSaharan Africa region ${ }^{4}$.

These programs where started due to increased training costs of specialists abroad, brain drain and an increasing demand for local specialists. The program's objective were to produce specialists locally who would be easier to retain and able to work in district hospitals. The training costs would be proportionately less. In this study, we review the outcome of the postgraduate program and assess whether the original intentions have been met to date.

\section{OBJECTIVES}

The purpose of the review was to determine the outcome of postgraduate training in the Master of Medicine programs at the University of Zambia School of Medicine since its' inception in 1982.The outcome is the primary and secondary objectives of the M.Med program as defined in 1981 by the University of Zambia senate ${ }^{1}$. The primary objective was to train specialists in clinical medicine to work in district hospitals in Zambia. The secondary objective was to train specialists to work in public hospital in Zambia, such as provincial, general and specialist hospitals.

The study set out to determine the number of graduates produced from 1986, when the first graduates completed their training to the most recent graduation in June 2007. The study ascertained where graduates are working and the type of practice they are involved in. This was compared to the objectives intended for the programme.

\section{METHODS}

The administrative offices of the University were used to retrieve all student records for postgraduate trainees in the school of Medicine from 1982 to 2007. All trainees were individually followed through the health system records, the use of close colleagues and friends to determine the current place and nature of practice of the trainees. A computer based data base was created of all trainees from the records obtained.

Using Microsoft Excel 2003, the general epidemiological data was analyzed, to determine the number of students, the sex proportions, the annual production rates, proportion by specialty, the location of practice and the scope of practice.

In addition the data was analyzed in relation to 3 possible outcomes of the training. These were grouped as:

1. The desired outcome of training was met by the trainee

2. An acceptable outcome of training was met by the trainee

3. No acceptable training outcome was achieved by the trainee

Outcome number 1 was defined as an M.Med trainee who has spent the majority of his practice in Zambia following qualification and has been in a permanent appointment at a Zambian district hospital during most of that period (in keeping with the primary objectives set out for the M.Med training program)

Outcome number 2 was defined as an M.Med trainee who has spent the majority of his practice in Zambia following qualification and has been in a permanent appointment in a Zambian government hospital during most of that period (that is a provincial, general ,teaching or specialist hospital)

Outcome number 3 was defined as an M.Med trainee who has achieved neither 1 nor 2 and is either in practice outside the country, in private practice in Zambia, not in active medical practice(that is working in a non medical field, or in a purely administrative position with no clinical practice) or working in a non government hospital(such a private hospital)

Trainees who were deceased were scored based on their period of practice. Trainees who were awarded qualifications posthumously were excluded from the study. 


\section{RESULTS}

Do we know how many were enrolled out of which 118 eventually graduated?

A total of 118 M.Med graduates were produced over the 22 year period. An average of 5 graduates were produced per annum over the period. Of these, 89 were male and 29 were female a ratio of 3 to 1.There a total of 107 Zambians and 11 non Zambian trainees a ratio of 9.7 to 1 . The graduates ranged from a minimum of Zero in 1991 to a maximum of 19 in 2001 (figure1).

\section{M.Med graduates 1986-2007}

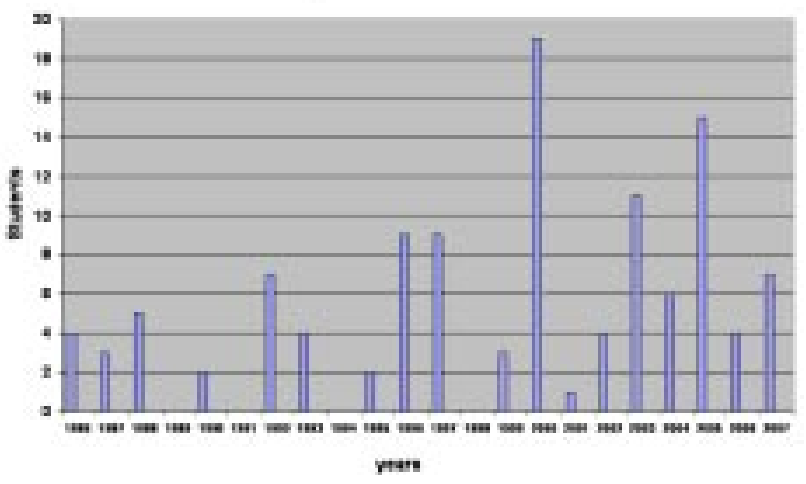

Unıcorre jrorr speciaııes

The largest group were 34 (29\%) who did General Surgery, followed by Paediatrics 29 (25\%). Medicine 27 ( $23 \%$ ), Obstetrics and Gynaecology 24 (20\%) and orthopaedics $4(3 \%)$..(figure 2 ).

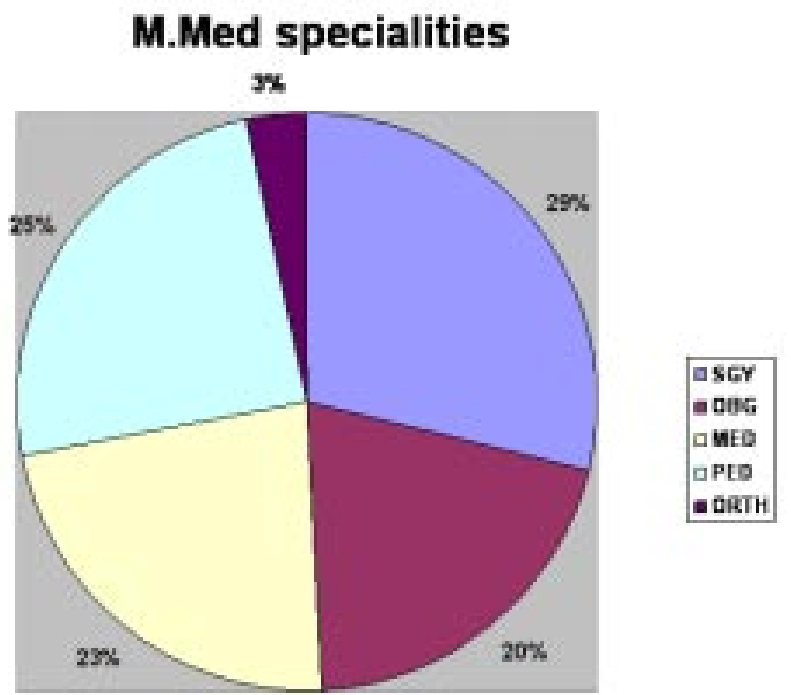

Of the 118 graduates $13(11 \%)$ have migrated abroad.. Seven (6\%)graduates have died.(figure 2 )

\section{location of practice}

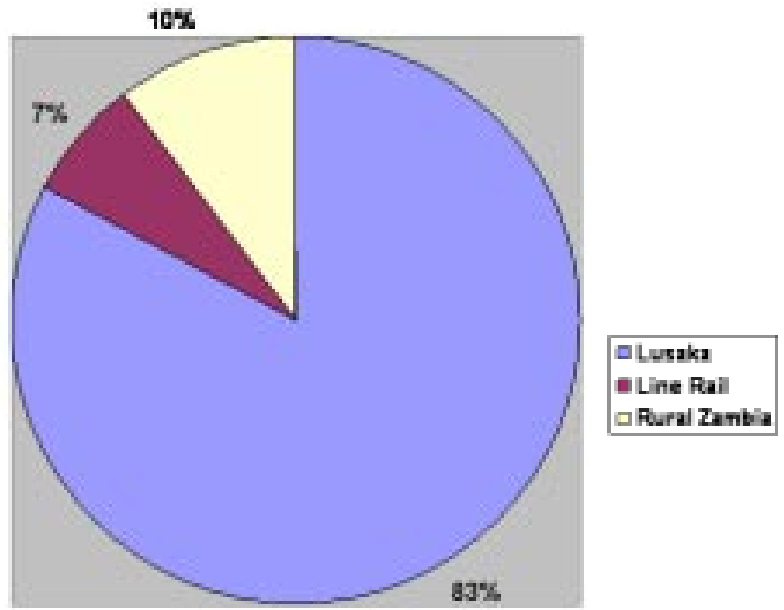

\section{Place of Deployment}

Of the 98 graduates who are working in Zambia, $81(83 \%)$ are working in Lusaka and $7(10 \%)$ along the line of rail in the 5 most urbanized towns in the country. Only $5(7 \%)$ are working in the rural areas of Zambia (figure 3). Of the 81 graduates working in Lusaka 47(69\%) are working at the University Teaching Hospital(UTH), 13(16\%) working with non governmental organisations doing non clinical administrative/public health work, 6(7\%) are working at the specialist Army Hospital, 6(7\%) are working at the University of Zambia school Medicine, 4 (5\%) are working in private clinics, $4(5 \%)$ are doing non clinical administrative/public health work at the Ministry of Health and one (1\%) graduate is working at the District Urban clinic (figure 4). 


\section{Graduates in Lusaka}

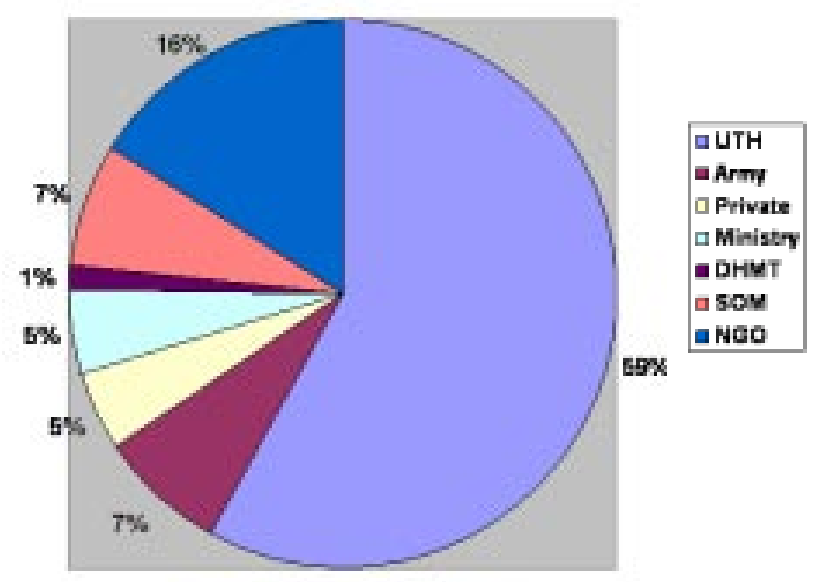

Type of practice

Overall $55(47 \%)$ are working in specialist hospitals, $25(21 \%)$ are not in clinical practice and are doing administrative jobs. $12(10 \%)$ are in private practice, $5(4 \%)$ are working in provincial hospitals and $1(1 \%)$ is district hospitals (figure 5).

In relation to the initial objectives of the M.Med training program slightly under $1 \%$ have achieved the primary objective of the program. $43 \%$ have achieved a secondary objective of the program and $57 \%$ have achieved an outcome not intended by the program (table 1).

\section{Training Outcome based on training objectives}

\begin{tabular}{|l|c|}
\hline Outcome & M.Med students \\
\hline Desired outcome & 1 \\
\hline Acceptable outcome & 60 \\
\hline Undesirable outcome & 50 \\
\hline Total & 111 \\
\hline
\end{tabular}

Desired outcome achieved $<1 \%$

Acceptable outcome $=54 . \%$

Undesirable outcome $=45 \%$

\section{7 trainees died and are excluded from the analysis}

\section{DISCUSSION}

The University of Zambia school of Medicine has produced 1276 doctors since the first graduates in 1973. In contrast it has produced only 118 postgraduate doctors. This means only about $9.24 \%$ of undergraduates trainees are completing postgraduate training. The institution graduates an average of 36 primary physicians every year, and only 5 specialist doctors every year.

It is rather modest compared to the volume of graduates produced by other African and subSaharan African countries whose programs are older and where the population pools are larger ${ }^{5,6,7}$.

The male to female ratio of $3: 1$ in the programme is comparable to that seen in other studies looking at female populations among doctors ${ }^{7}$.

It is noted that the largest number of graduates are in the General Surgery discipline at $29 \%$ of graduates. Some postgraduate programs in Africa have shown predominance of internal medicine and obstetrics in their pool of graduates ${ }^{5,6}$.

This finding, may reflect the greater demand for this type of specialty in the population and also the greater strength of the surgical department in Zambia, as well as in the region.

The influence of the new regional College of Surgeons of East and Central Africa has served to promote surgical training among young doctors in the region $8,9,10,11,12,13$.

A modest level of brain drain at $11 \%$ was observed in the M.Med programme. Compared to the Ministry of Health estimates of an annual attrition rate of $4.2 \%$ from the undergraduate program.. It is estimated that up to total of $300(28 \%)$ doctors trained in Zambia are practicing in the United Kingdom $12,13,14,15$. The World health organization estimates an attrition of $91 \%$ among medical graduates sent for specialist training abroad ${ }^{16,17,18}$. In comparison to this only 13 postgraduate students are working abroad. I do not think its essential to differentiate who is Zambian or non-Zambian The actual migration of Zambians from the M.Med programme is only 7 $(5.9 \%)$. 
The deployment of trainees shows concentration in the highly urbanized central areas of the country with the large majority of trainees working in the capital city $81(83 \%)$. Very few of them are in the rural parts of the country.

There is a similar trend is among $\mathrm{MBChB}$ graduates where $71 \%$ are in Lusaka and the Copperbelt province $^{19,20}$. This is not peculiar to Zambia, but is common in many African countries ${ }^{21}$.

The University Teaching Hospital Lusaka (UTHL) has retained the largest number of M.Med graduates. Forty-seven (59\%) of the M.Med graduates are practicing at the UTHL.

Even though the M.Med programme was initially intended to provide district specialists through out the country, most posts in ALL hospitals remain unfilled. At the UTHL, 50\% of positions are unfilled. Trainees have inevitably taken up these appointments, a scenario, not anticipated by the senate of the University ${ }^{20,2122}$.

Therefore the Master of Medicine graduate has unintentionally become lecturer, trainer and lead specialist. There is a variance of over $22 \%$ between the establishment for doctors in Zambia and the actual appointments. Excluding expatriates increases this variance upto $60 \%{ }^{21}$.

Innovative strategies of redistribution,joined up thinking and special incentives will be required to promote equitable distribution of specialists in the country.

Redeployment or Internal brain drain has become a problem particularly in relation to health related Nongovernmental Organisations (NGOs) in the country and the central Ministry of Health. Both attract M.Med graduates creating an internal brain drain from the clinical to non clinical positions. The problem is significant because up to $25 \%$ of the M.Med graduates leave the public sector to work with the NGOs in lucrative administrative positions. This is detrimental to safe clinical care and appropriate planning in the public hospitals. There twice as many graduates leaving clinical practice to join NGOs than they are graduates leaving the country to practice abroad.
Solutions to this problem have included, the setting up of the Masters of public health program in 1991. This program is now the largest program in the school. Applications exceed annual intake by as much as $300 \%$. The Ministry of Health has a rural retention directed at $\mathrm{MBChB}$ graduates which is planned to extend to M.Med graduates. Another solution is to encourage regular clinical work by those who opt out of public work ${ }^{22}$.

Zambia is one of 24 countries on the African continent with a single medical school which has suffered high migration rates of medical doctors ${ }^{23}$.

There is a growing body of evidence that local post graduate training tends to stem the external brain drain. This is evident in the Zambian case ${ }^{23,24}$.

Further study is needed to assess the reasons for the internal brain drain. This would inform retention or collaborative programs between the graduates. This could potentially avoid repetition in collaborative work amongst the healthcare related NGOs.

\section{REFERENCES}

1. University of Zambia School of Medicine Handbook, 2000, UNZA press.

2. University of Zambia Calendar 2007-2008. UNZA 2007 University of Zambia press, Lusaka

3. World Health Statistics. Zambia Country profile 2006.http://www.who.int/whosis/en

4. University of Zambia. School of Medicine postgraduate regulations 2000 UNZA press Lusaka.

5. Ike S. The problems of postgraduate medical training in Nigeria. Niger J Med. 2004 OctDec;13(4):412-8.

6. Ohwovoriole AE, Obembe AA review of the results of the examinations for Fellowship of the Nigerian Postgraduate Medical College (1972-84). Medical Education.1987 May;21(3):250-4.

7. Sandhu B, Margerison C, Holdcroft A. Women in the UK academic medicine workforce. Medical Education. 2007 Sep; 41(9):909-14.

8. Broadhead RL, Muula AS. Creating a medical school for Malawi: problems and achievements. BMJ. 2002 August 17;325 (7360):384-387. 2. 
9. Banda S, Yikona J. Medical education. Lancet. 2001;358:423.

10. Evans C M Urolink in Subsaharan Africa $B J U$ International 200289 (suppl 1.) 6-10.

11. Evans C, Rahima Dawood Memorial Lecture 2002: Surgical training in Africa. East and Central Africa Journal of Surgery, 10(2): 5-9.

12. Beveridge M. Surgical Training in East Africa 2004 June 26, 363.2196.

13. Muula A S, Surgical Activities in Hospitals in Malawi. Tropical Doctor. October 2007.37.272.

14. Kachimba J S and Mwaba P. The Human resources for health crisis in Zambia: deaths, departures, demoralizing conditions of service and disinterested diaspora. Medical Journal of Zambia (2007) 34:1; 5.

15. Miti S. The Human resources crisis in the Health sector in Zambia and efforts by the Ministry of Health to address the crisis. Medical Journal of Zambia (2007):34:1:6-8.

16. Schatz J J. Health Worker Crisis in Zambia 2008 Lancet 371 638-639.

17. Bowa K, Health Worker Crisis in Zambia. Lancet 2008 May 10; 371(9624):1577-8.
18. Yikona J. Sustaining Medical Education is difficult in poor countries. British Medical Journal 2003 January 4. 326(7379):51.

19. Ministry of Health Human Resources for Health strategic plan 2006-2010, GRZ.

20. Price M, Weiner R. Where have all the doctors gone? Career choices of Wits medical graduates S Afr Med J. 2005 Jun;95(6):414-9.

21. Ministry of Health Annual Training and Development Plan, MOH, GRZ 2008 Lusaka

22. Laing R O, Todd C H. Postgraduate district training in Zambia. Lancet.1993. Apr 10;341(8850):966.

23. Eastwood J B, Conroy R E, Naicker S, et al. Loss of Health Professionals for sub-Saharan Africa. The pivotal role of the UK. Lancet 365 May 28. 1893-1900.

24. Makasa E. Africa's medical brain drain. Why I want to stay in Africa. British Medical Journal 2005; 331(7519):780-1. 